Mani Tebet Azevedo de Marins Universidade Federal Rural do Rio de Janeiro, Seropédica, RJ, Brasil

\title{
O 'feminino' como gênero do desenvolvimento
}

\begin{abstract}
Resumo: Este artigo propõe analisar, sob o viés de gênero, como se desenvolve, de modo não premeditado, a construção de fronteiras morais e simbólicas decorrentes da implementação de um programa de combate à pobreza: o Bolsa Família. Doravante, procuraremos esclarecer as propriedades dessas fronteiras e as formas de negociação de seu conteúdo. Com a finalidade de compreender melhor a complexidade da formação do status das beneficiárias (mães), percorremos diversos espaços pelos quais elas transitam. Por meio de entrevistas realizadas em uma periferia de uma grande cidade do Rio de Janeiro, podemos afirmar que as relações entre beneficiário(a)s e não beneficiário(a)s fundam-se em uma matriz moral carregada de tensões valorativas de gênero ('boa' e 'má mãe'), o que acaba por reproduzir também uma hierarquização do 'bom' e do 'mau pobre'.
\end{abstract}

Palavras-chave: Gênero; fronteira simbólica; Programa Bolsa Família

\section{Introdução}

Muitos autores consideram que, na modernidade, as políticas públicas têm oscilado entre focar o indivíduo ou a família como sua unidade de ação (Ben FINE et al., 2001; Verónica SCHILD, 2007 e Jane JENSON, 2009). Os laços entre Estado e Família se assentam em uma duradoura e complexa história de conflitos e compromissos morais/legais. O Estado sempre oscilou sua intervenção entre indivíduo e família; esta, durante muito tempo, considerada como a primeira forma de poder. Aos poucos, o Estado vai centralizando o poder para si e, recentemente, ele passa a redistribuir seu poder com ela, através de políticas sociais.

Em especial, a partir da década de 1990, ocorre uma reorganização das responsabilidades entre Estado, mercado, comunidade e família. O controle direto da implementação de políticas públicas pelo Estado foi, crescentemente, cedendo lugar a diferentes formas de parcerias e de divisão de responsabilidades com organizações não governamentais (ONGs), igrejas, comunidades, famílias e com os beneficiários individualmente.

\section{(c) (7)}

Esta obra está sob licença Creative Commons. 
Nas suas mais variadas configurações, a família pode ser considerada uma categoria das políticas públicas latino-americana e de alguns países da Europa, tais como: França, Espanha, Itália. Os pressupostos de responsabilidade e participação social dessas políticas sociais se assemelhariam nestes países no que tange ao aspecto da focalização na família como um ator importante para a resolução de problemas sociais.

Fundamentalmente, a família se inscreve na concepção de proteção social desses países que a pressupõem como unidade básica no estabelecimento de laços de solidariedade. Tal modelo se diferencia, por exemplo, dos modelos americano, alemão e inglês, nos quais a política centraliza o indivíduo como foco de suas ações. No que se refere ao modelo brasileiro, Elijah ANDERSON (1999) o denomina como 'familista', cuja valorização se encontra atrelada mais às formas familiares tradicionais do que ao indivíduo estrito senso como portador de direitos.

Mesmo que o Estado (com a participação de ONGs e do terceiro setor) ainda seja o maior interventor na esfera das políticas públicas, tem sido atribuído à família (sobretudo à mulher) o papel de gerenciamento dos recursos transferidos e também do cumprimento de responsabilidades específicas. Em 1986, a Assembleia Geral da ONU produziu uma Declaração sobre o Direito ao Desenvolvimento, da qual extraímos dois artigos que se alinham com a discussão de participação e responsabilidade:

\section{Artigo $2^{\circ}$}

$\S 1$. A pessoa humana é o sujeito central do desenvolvimento e deveria ser participante ativo e beneficiário do direito ao desenvolvimento.

§2. Todos os seres humanos têm responsabilidade pelo desenvolvimento, individual e coletivamente, levando-se em conta a necessidade de pleno respeito aos seus direitos humanos e liberdades fundamentais, bem como seus deveres para com a comunidade, que sozinhos podem assegurar a realização livre e completa do ser humano e deveriam por isso promover e proteger uma ordem política, social e econômica apropriada para o desenvolvimento.

\section{Artigo $8^{\circ}$}

§1. Os Estados devem tomar, em nível nacional, todas as medidas necessárias para a realização do direito ao desenvolvimento, e devem assegurar, inter alia, igualdade de oportunidade para todos no acesso aos recursos básicos, educação, serviços de saúde, alimentação, habitação, emprego e distribuição equitativa da renda. Medidas efetivas devem ser tomadas para assegurar que as mulheres tenham um papel ativo no processo de desenvolvimento [...] [grifo nosso].

No que tange à relação entre Sociedade e Estado, a ONU estabelece ao mesmo tempo um direito e um dever. Assim, os indivíduos têm o direito de serem beneficiários de políticas públicas, mas como dever eles devem exercer um papel ativo de participação frente ao desenvolvimento. Mesmo se a noção de "indivíduo" possa aparecer de forma abstrata e geral ("pessoa humana" e "ser humano"), tal declaração especifica normativamente as mulheres como aquelas que devem colaborar com o desenvolvimento.

Atualmente, há continuidades e adaptações políticas no uso da família como objeto (e ator) da intervenção pública. De acordo com Pierre STROBEL (2008, p. 52-53), na contemporaneidade, emergem duas contradições no âmbito das políticas sociais. A primeira vinculada ao fato de que, apesar do declínio da família como forma única de socialização inicial, o Estado a realoca num papel fundamental para o restabelecimento dos laços sociais. Diante disto, o Estado prevê que a família (sobretudo a mulher) tenha um papel essencial no 
cumprimento das necessidades coletivas e, mais do que isso, no estabelecimento da coesão social. A segunda contradição se apresenta na ideia de que, ao mesmo tempo em que política faz parte de um projeto liberal (e modernista) - no qual as mulheres aumentaram sua participação no mercado de trabalho - ela pressupõe que a mulher mantenha a função social de cuidadora, reinstalando assim o papel tradicional de gênero.

No que diz respeito à implementação das políticas públicas, o Estado passa (principalmente nos anos 90) a redistribuir suas responsabilidades com três entes principais: o mercado, a comunidade e a família. Assim, de acordo com Bila SORJ e Carla GOMES (201 1 , p. 147), a centralidade das políticas nas mãos do Estado vai perdendo força para novas configurações de parcerias com ONGs, empresas privadas, líderes comunitários, igrejas e, até mesmo, com os próprios beneficiários - que passam a ter maior controle na administração dos recursos e da própria política. Este novo paradigma das políticas sociais é classificado de variadas formas pela literatura sociológica: Pós-Consenso de Washington (FINE et al., 2001), cidadão consumidor (SHILD, 2007) e investimento social (JENSON, 2009).

Além da descentralização do poder estatal e do compartilhamento de gastos sociais com outras instituições e atores, Thomas OLK (2006) aponta para uma mudança temporal na formulação das políticas sociais, cuja prerrogativa "investimento social" (ou, ainda, "quebra do ciclo intergeracional da pobreza") indica uma ação voltada para o alcance futuro de bem-estar coletivo. Esta nova formulação de políticas precede inúmeras discussões e disputas que atravessam as fronteiras dos Estados-Nação.

Ao mesmo tempo em que a política volta suas ações para a família (de forma não necessariamente contraditória) observamos, na política social, um incentivo ao processo de individualização (ou do estabelecimento de "capacidades" ou "autonomia"), através do qual caberia ao indivíduo se livrar da sua situação de precariedade social, cumprindo de maneira "responsável" as contrapartidas da política. No debate contemporâneo sobre o papel do Estado no desenvolvimento econômico e social, diversos instrumentos analíticos (capability, empowerment, governança, capital humano e social) aparecem como forma de acionar esta nova forma de cidadania baseada em valores de cooperação.

Essas mudanças aparecem de forma mais visível nas políticas de desenvolvimento, de renda mínima e de combate à pobreza, nas quais o beneficiário (ou a beneficiária) deve construir estratégias (com o auxílio monetário) para superar sua situação de vulnerabilidade social. A inserção dos beneficiários nos programas sociais passa a ser feita por meio de um contrato (formal ou informal) de compromissos que eles(as) assumem com o Estado. Neste momento, grupos que trabalhavam sobre a análise cultural das políticas de desenvolvimento (sobretudo das políticas de combate à pobreza) estavam crescendo e se legitimando. Neste novo terreno - mesmo sendo ainda um espaço dominado pelo âmbito do Banco Mundial - foi criada, durante os anos 90 , uma unidade especializada nas discussões de gênero.

A designação da mulher em seu papel social de mãe no âmbito das políticas sociais é classificada por Ann Shola ORLOFF (2005) como 'política maternalista'. Esta visão também é compartilhada por Marília FONSECA (1998, p. 9-10), que caracteriza as políticas de transferência de renda no Brasil como 'generificadas'. Nesse sentido, como podemos notar, apesar do estabelecimento de convenções e de declarações para a redução das desigualdades de gênero, as políticas vêm reproduzindo padrões tradicionais relacionados à família, à pobreza e ao gênero. Tais normas e diretrizes internacionais tendem a se apresentar de modo ressignificado no contexto local, sobretudo as normas de gênero que, em geral, se apresentam de modo informal no âmbito das interações cotidianas.

Para tentar dar conta destas problemáticas, tomamos como objeto em nossa pesquisa o Programa Bolsa Família - que prioriza as mulheres como corresponsáveis (e 
titulares legais) do Estado no combate à pobreza. Gostaríamos de compreender neste nível de análise em que medida os profissionais do Estado tipificam a população de baixa renda e os(as) 'merecedores' do benefício, além de buscar entender a lógica pela qual os agentes implementadores do Bolsa Família produzem tais tipificações, ou seja, quais seriam os instrumentos (burocrático, econômico, moral e/ou conhecimento dos candidatos) acionados para legitimar e certificar suas posturas.

Apresentaremos, ainda, os critérios de justificação usados pelos beneficiários(as) para explicar o fato de serem 'merecedores' do benefício e a maneira pela qual percebem sua trajetória após receberem um recurso assistencial. Sofrem constrangimentos e/ou controles particularmente relacionados à sua posição de dependentes do Estado? Buscamos aqui apreender o movimento de constituição da "carreira moral" dos beneficiários, quando o "controle disciplinar" (Erving GOFFMAN, 1987) passa a ser exercido sobre eles(as) na esfera pública. A ideia, então, é pensar como se cria, a partir de uma identificação formal e informal, uma imagem pública dos beneficiários(as), através da qual estes precisam ser moralmente vigiados(as), controlados(as) e, até mesmo, punidos(as), se necessário (Michel FOUCAULT, 2009).

Em seguida, buscaremos esclarecer as propriedades dessas fronteiras simbólicas e as formas de negociação de seu conteúdo. Em específico, pormenorizaremos a construção de três tipos de fronteiras morais: 1) fronteiras entre 'beneficiários legítimos' e 'beneficiários ilegítimos'; 2) 'fronteiras de legitimidade no interior da família beneficiária' e 3) 'fronteiras interfamiliares'. Com a finalidade de compreender mais adequadamente a complexidade da formação do status dos(as) beneficiários(as) do Bolsa Família, realizamos observação participante e entrevistas com atores que, de alguma forma, se relacionam com os(as) beneficiários(as). O lócus da pesquisa foi uma periferia da região metropolitana do Rio de Janeiro chamada Itaboraí. Lá percorremos e avaliamos diversos espaços por onde estes beneficiários passam, tais como: escolas, postos de saúde, coordenação do Bolsa Família e o setor de cadastramento, Centro de Referência de Assistência Social (CRAS), restaurante popular e a própria vizinhança.

Importante mencionar que nossos resultados de pesquisa diferem de outros trabalhos, em particular porque não foram realizados em grandes metrópoles, ao contrário, a maioria em espaços rurais, onde a construção sobre emancipação, liberdade e cidadania aparecia de forma mais clara entre as beneficiárias. Podemos citar particularmente, neste contexto, os trabalhos de Walquiria G. Domingues Leão REGO \& Alessandro PINZANI (2013), Flávia PIRES \& Rego (2013). ${ }^{1}$

Os resultados nos revelam que as relações estabelecidas entre beneficiários e não beneficiários (atores institucionais e vizinhos) fundam-se em uma matriz moral, com a presença de fofocas, julgamentos morais e controles sociais específicos que se desenvolvem em torno da figura do beneficiário. Importante salientar que entrevistamos a família beneficiária como um todo (cônjuge e filhos - crianças e adolescentes) e não apenas as mulheres (mães) titulares legais dos benefícios. Com base neste estudo sobre as interações cotidianas dos 'pobres', vemos progredir um processo de diferenciação simbólica entre pessoas que dependem do serviço de Assistência Social e pessoas que não dependem de tal serviço.

\footnotetext{
' Além disto, em outra pesquisa realizada em áreas urbanas em outros Estados como, por exemplo, a de Antônia Jesuíta de LIMA (2003), as falas das beneficiárias não apresentam o mesmo tipo de discurso moralizante registrado aqui neste paper. Neste sentido, parece que não é possível generalizar para todo o território nacional os resultados das pesquisas nas áreas rurais, nem aqueles referentes aos espaços urbanos. De fato, parece haver efeitos específicos da transferência de renda na vida dos beneficiários - dependendo da localização socioespacial.
}

4 Revista Estudos Feministas, Florianópolis, 26(1): e39010 


\section{A construção de fronteiras simbólicas}

Tanto as discussões públicas quanto acadêmicas sobre o Programa Bolsa Família (PBF) centralizam os debates sobre a eficácia do Programa. Mais especificamente, analisam a focalização na população considerada 'pobre', o cumprimento das condicionalidades relativas à frequência escolar das crianças e o acesso à saúde e à segurança alimentar. Isto é, a maior parte dos estudos até aqui produzido se dedica, sobretudo, a analisar os impactos do PBF sobre a população beneficiada, ou seja, objetiva aferir o grau de aproximação ou de distanciamento dos resultados obtidos frente às metas estabelecidas pelo próprio Programa. Nosso interesse em pesquisar o Bolsa Família possui outro arranjo analítico. Gostaríamos de contribuir com discussões em torno das políticas públicas como um conjunto de concepções e ações que afeta a sociedade, ou parte dela, para além de seus objetivos declarados. Tais consequências podem ser de natureza simbólica, inscrevendo-se no tecido relacional de uma comunidade, gerando novas formas de conflitos entre os grupos sociais.

A questão fundamental deste artigo é analisar como se processa a construção de distinções sociais entre grupos que, apesar de compartilharem uma origem socioeconômica similar, acabam se diferenciando moralmente pela relação de (in)dependência de um Programa de Assistência Social.

\section{'Beneficiários legítimos' e 'beneficiários ilegítimos'}

No domínio do trabalho de campo podemos notar a emergência de várias classificações sociais, dentre elas a distinção 'trabalhador' e 'vagabundo'. Estas duas categorias de oposição acabam produzindo outra diferenciação de cunho moral que divide 'pobres beneficiários(as) legítimos' ('boas mães') e 'pobres beneficiários(as) ilegítimos' ('más mães'). De modo geral, os atores institucionais não veem os beneficiários como 'aproveitadores' do sistema, como apontam alguns dos não beneficiários(as) (tendo como exemplo paradigmático, como veremos, a fala de Salvador ${ }^{2}$ ). De acordo com os atores institucionais, os(as) beneficiários(as) teriam dificuldades para aproveitar as oportunidades que o Governo oferece.

As classificações sociais também se constroem a partir das atitudes em relação à oferta dos cursos de capacitação. No que se refere a um destes cursos, localizado no Complexo Petroquímico do Rio de Janeiro (COMPERJ), Paula (Estagiária de Serviço Social) afirma que: "Lá na COMPERJ foi uma dificuldade para formar turma. Foi um problema, porque eles ligavam para os beneficiários e tal, ninguém se interessava muito e tinha que ter segundo grau e era difícil alguém ter segundo grau". Neste caso, podemos atentar que são as exigências dos cursos - e não características meramente pessoais - que impedem os(as) beneficiários(as) de agir, na medida em que estes(as) (em sua maioria) não possuem o grau de escolaridade exigido para a capacitação. ${ }^{3}$ Vale a pena ressaltar que, no conjunto nacional dos(as) beneficiários(as) do PBF, a maioria não completou o Ensino Médio. ${ }^{4}$ Os cursos oferecidos pelo Município eram de eletricista e soldador, cursos tipicamente

\footnotetext{
${ }^{2}$ Todos os nomes foram trocados como forma de preservar a identidade dos entrevistados.

${ }^{3} \mathrm{Em} 2010$, de acordo com Jorge Abrahão de CASTRO e Lúcia MODESTO (2010), apenas $11,1 \%$ dos titulares legais das famílias beneficiárias possuíam o Ensino Médio completo, sendo a maior proporção concentrada no nível do Ensino Fundamental incompleto $(65,1 \%)$. Estes dados foram produzidos a partir dos microdados do Cadastro Único de março de 2010.

${ }_{4}^{4}$ Castro \& Modesto (2010, p. 264), a partir de microdados do Cadastro Único de março de 2010, mostram (através de uma publicação feita pelo IPEA) que cerca de $70 \%$ dos beneficiários acima de 25 anos possuem apenas o Ensino Fundamental incompleto.
} 
direcionados ao gênero masculino, o que, em alguma medida, inviabiliza uma maior autonomia para as mulheres beneficiárias. Em relação aos cursos, segundo Paula (Estagiária de Serviço Social),

[...] parece que era muito bom e é um curso até caro, né, para pagar, mas tem esse critério de segundo grau. [...] Eu não lembro quantas vagas, mas os beneficiários não procuraram e tiveram que abrir as vagas para toda a comunidade. Então, estão acomodados. Uma acomodação da maioria das pessoas. São pessoas bem pobres e a maioria não quer estudar, não quer fazer curso.

O discurso de acomodação de Paula (no que se refere particularmente ao esvaziamento do curso) se contrapõe, por um lado, à exigência do diploma de Ensino Médio completo e, por outro, à precária divulgação de tal curso: "Esses cursos só foram divulgados de boca a boca. O curso do colégio, por exemplo, às vezes, eles mandam um papel pra gente divulgar pra quem tinha o Bolsa Família. E a gente avisa durante a visita nas casas. Mas não havia cartaz não". Não obstante, Paula afirma que os beneficiários apresentam justificativas pouco convincentes para não participar das qualificações profissionais: "Eles inventam desculpa... que teve que sair ou ir no médico. Eu já avisei um, duas vezes. A responsabilidade é deles".

Embora possa haver outras razões para a não participação dos bolsistas nos cursos oferecidos, a exigência do diploma de nível médio (capital educacional raro entre os beneficiários) e a falta de divulgação dos cursos, a Estagiária Paula atribui a não frequência por razões de ordem moral. O fato de a política de assistência instaurar no município cursos de capacitação para o público (prioritariamente masculino) faz nascer um sentimento de injustiça social entre aqueles não beneficiários(as) (sobretudo trabalhadores pobres) que, em princípio, não teriam direito a se qualificar de forma gratuita. Segundo Salvador (não beneficiário), esse tipo de curso deveria ser oferecido para aqueles que realmente possuem interesse, descartando, assim, a escolha de fazer o curso por uma exigência do Programa.

No que tange ao merecimento do benefício, parece que, independentemente do status de grupo (beneficiário, não beneficiário e atores institucionais), as pessoas imputam tal merecimento àqueles que necessitam financeiramente deste apoio estatal. Ou seja, a ideia é que somente os mais 'necessitados' poderiam solicitar este auxílio, devendo aproveitar o recurso para sair da situação de dependência. Para Mara (não beneficiária), por exemplo, os 'necessitados' são aqueles que passam fome. Assim, ela preferiu não solicitar o benefício, porque, mesmo precisando, acha que: "quem merece são aquelas famílias que não têm nem um pão para comer".

Observamos que os beneficiários que 'não passam fome' são lidos como 'aproveitadores' tanto pelos aposentados quanto pelos trabalhadores. Em geral, quem vê os beneficiários como 'merecedores' são pessoas que sofreram mais com as flutuações no mercado de trabalho. Logo, aqueles que tiveram uma relação mais duradoura e consistente com o mercado de trabalho constroem uma fronteira simbólica entre 'eu' e 'eles'. Notamos, assim, que o trabalho ocupa um lugar social importante para que algumas pessoas se distanciem da classificação de beneficiários, estigmatizando-os como 'aproveitadores'.

Entre os beneficiários, Jucélia, por exemplo, acredita ser muito complicada a percepção de que "quem recebe o Bolsa Família quer dinheiro fácil". Segundo ela, esta ideia pré-concebida não corresponde à realidade da maioria, pois "se a pessoa pede é porque precisa". Particularmente, no que diz respeito à categoria de 'aproveitador' do sistema de proteção social, ela afirma que: "Tem gente que fica falando que a gente aproveita que o Governo tá dando, mas aqui não tem ninguém com carro e casa boa não, a gente pede porque precisa mesmo".

6 Revista Estudos Feministas, Florianópolis, 26(1): e39010 
Reaparecem, portanto, aqui, as oposições de classificação já apontadas anteriormente, quais sejam: 'merecedor' ('necessitado') x 'aproveitador' ('não necessitado'). Esta última categoria se expressa, também, por aqueles que não investiriam o recurso do Bolsa Família corretamente, ou seja, que aproveitam o dinheiro para investir em si próprios ou realizar compras para sustentar um vício. O mais intrigante é que os próprios beneficiários possuem sistemas de classificação sobre outros beneficiários. Nesse sentido, vemos que o discurso de Maria (beneficiária) vai ao encontro de outras ideias correntes, ${ }^{5}$ como aquela relacionada à acomodação e à possibilidade de as mulheres aumentarem o número de filhos para aumentar o valor do benefício. Vejamos: "Eu acho que tem umas que fazem filho só para ganhar os $\mathrm{R} \$ 22,00$ reais, né? Tem muita falta de informação. Muitas não pensam em gastar com os filhos... é cigarro, bebida, balada. É por isso que eu acho que tem que ter Assistente Social em cada casa para saber" (Beneficiária Maria).

Já outra beneficiária, Simone, salienta que - no âmbito de suas interações - escuta expressões estereotipadas (e também críticas) em relação à figura do beneficiário e cita o exemplo da fila na casa lotérica:

O Governo não tem vergonha na cara de ficar dando essa mixaria pro povo. Se fosse eu, nem pegava!" Aí eu fico na minha, pensando assim: Deus sabe de todas as coisas. Enquanto eles não querem, muita gente precisa. Às vezes, muita gente que tem não valoriza o que tem e não usa adequadamente. Elas falam porque não precisam receber, né? Eles não recebem.

Mas, ao mesmo tempo, ela afirma que existem beneficiários(as) que também acreditam que o dinheiro é muito baixo e nem vale a pena lutar por ele. Por isso, "muitas vezes eles pedem pra outras pessoas ficar na fila e pegar o dinheiro. Acho que por vergonha... O dinheiro pode até ser pouco, mas ajuda, né? A gente precisa".

Os beneficiários(as) também percebem uma distinção, ainda que escalonada, entre 'merecedores(as) e 'aproveitadores(as)' do PBF, o que os conduz a julgamentos morais específicos no contexto da interação. Assim, os 'merecedores(as)' do Bolsa Família variam de pessoas desempregadas (mas que trabalharam ao longo da vida) a pessoas necessitadas (que passam por constrangimentos graves de pobreza ou possuem na família uma enorme quantidade de filhos) - aqui vemos a ideia de que as crianças precisariam de um suporte externo (a criança como 'ser frágil' deve ser cuidada). Já os 'aproveitadores' variam de pessoas que nunca trabalharam (sendo julgados como 'acomodados') ou que não possuem uma condição de extrema precariedade financeira, a sujeitos que não investem naquilo que é considerado moralmente como 'correto', ou seja, na família e, principalmente, na educação das crianças.

O julgamento de 'merecedor' ou 'aproveitador' soma-se a outro processo de julgamento moral relacionado à avaliação das práticas das beneficiárias frente à maternidade, derivando daí categorias de 'boa' ou 'má mãe'. Este tipo de percepção advém tanto dos atores institucionais quanto dos não beneficiários e, até mesmo, dos beneficiários que qualificam positivamente a mãe, neste caso entendida como uma responsável, quando ela faz um investimento coletivo, solidário e 'correto'. Já a qualificação de 'má mãe' ou de 'mãe irresponsável' se dá quando a beneficiária investe em si própria ou não cumpre as condicionalidades do programa referentes às crianças e aos adolescentes. Vejamos alguns exemplos desse tipo de classificação social.

Uma beneficiária de codinome Edilceia relata que sua própria família precisa 'estar no perfil' (e precisa investir nas crianças), caso contrário, a vizinhança passa a julgá-la e a

${ }^{5}$ Podemos tomar como exemplo desta ideia corrente a Presidente de Pastoral da CNBB, que diz que Bolsa Família é "Assistencialista" e "vicia" (Carolina BRÍGIDO, 2006). 
desconfiar de sua condição de pobreza. De acordo com Edilceia, esta ética de conduta deveria reger todas as ações dos beneficiários. $\mathrm{E}$, neste ponto, refere-se à cobrança exercida pelas famílias não beneficiárias sobre as famílias beneficiárias:

Os daqui que eu sei que ganha, compra as coisas para os filhos, a pessoa não gasta com futilidade, porque isso aí é um dinheiro que o Governo deu para gastar com os filhos, né? Um tênis, um sapato, um caderno, um remédio... Todo início de ano, eu compro caderno grande que minha filha usa, compro lápis, borracha... Eu acho que eu aplico esse dinheiro neles.

Ao contrário, Cristina (não beneficiária) percebe o gasto de uma outra forma. Segundo ela, as mães utilizam o dinheiro para gastar com elas próprias: "Eu vejo que gastam para elas. Outro dia, eu vi uma bebendo e o filho largado. Ao invés de correr atrás, arrumar emprego...". Este discurso se contrapõe ao discurso da beneficiária Carla, que afirma utilizar o dinheiro para "pagar conta de mercado, biscoito, carne para as crianças. Aí, se dá, compro uma roupa". De acordo com Carla, "o pessoal lá da assistência fala: 'Você sabe que esse dinheiro é para as crianças, né?' Eles dizem que este dinheiro é para comprar roupa, material escolar, uma fruta, coisas assim, né?".

Verificamos neste contexto uma clara distinção de percepção entre beneficiária e não beneficiária no que diz respeito à oposição 'más mães' e 'mães responsáveis'. Salvador (não beneficiário, esposo de Cristina) parece fazer uma oposição mais clara ainda entre 'boas' e 'más mães' no que se refere ao conjunto de beneficiárias; estas últimas (que investiriam o dinheiro em si próprias) são vistas por ele de forma negativa, pois não estariam cumprindo seu papel tradicional de mãe. Sua compreensão de 'boa mãe' está pautada na ideia, similar àquela presente nos pressupostos morais do PBF, de que a beneficiária tem de ser solidária e investir prioritariamente nas crianças. ${ }^{6}$ Nesse caso, os beneficiários parecem ter noção daquilo que se espera deles como um comportamento de 'bom pobre'; por isso mesmo, manipulam conscientemente essa categoria. A noção de 'bom pobre' aparece como sinônimo de 'boa mãe', vinculada às características de altruísmo, dedicação, responsabilidade e cuidados.

Podemos notar que - para os três grupos de entrevistados (atores institucionais, não beneficiários e os próprios beneficiários) - duas categorias fundamentais emergem como forma de julgamento moral dos beneficiários, quais sejam: 'merecedor' e 'aproveitador'. A primeira se refere à compreensão de que a beneficiária merece o benefício, pois é lida como 'boa mãe': altruísta, justa e responsável. A categoria 'aproveitadora' está relacionada à beneficiária que é percebida como 'má mãe': egoísta, desviante e irresponsável. Quanto mais nos aproximamos da classificação de 'má mãe', maior será a desclassificação moral do beneficiário e, ao contrário, quanto mais próximo da categoria de 'boa mãe', maior será sua legitimidade como beneficiária do Bolsa Família. Nesse sentido, vemos nitidamente a existência de uma tensão valorativa de gênero no julgamento das beneficiárias que acaba por reproduzir também o processo de hierarquização do 'bom' e do 'mau pobre'.

\section{Fronteiras de legitimidade no interior da família beneficiária}

Procuramos analisar como se constroem fronteiras simbólicas (e disputas em torno da legitimidade da administração do benefício) entre membros de uma família beneficiária.

\footnotetext{
${ }^{6}$ Esta concepção do Programa também se encontra presente na Cartilha ofertada aos beneficiários no ato do cadastramento. Esta cartilha é quase um 'manual de comportamento' para as famílias beneficiárias, indicando como o titular legal (mulher/mãe) deve gerir seu benefício. Há indicações, também, sobre que tipo de alimento deve ser comprado e ingerido pela família, almejando o desenvolvimento nutricional das crianças.
}

8 Revista Estudos Feministas, Florianópolis, 26(1): e39010 
Em particular, investigamos como se processa a negociação do poder da titularidade entre pais (sobretudo mãe) e filhos (em especial os adolescentes) que tentam barganhar parte do dinheiro do Programa, sob o princípio de que o Bolsa Família é "direito das crianças". O questionamento da legitimidade materna em administrar o dinheiro parece ter como pano de fundo a crítica (mesmo que branda e interesseira), por parte dos adolescentes, sobre a dependência parental. Assim, por um lado, afirmam que deveriam ter autonomia para receber o benefício em seu nome; por outro, manifestam uma incompreensão de por que o dinheiro permanece com as mães, se o Programa tem como foco crianças e adolescentes.

Ao entrevistarmos a Professora Raquel, perguntamos-Ihe se havia conversas entre ela e seus alunos referentes ao Programa. Acenando positivamente com a cabeça, disse que, sempre que podia, informava aos alunos sobre seus direitos de pertencentes a uma família beneficiária.

Eu acho que o dinheiro deveria ser aplicado para os alunos, mas a gente não vê muito isso. Eles não têm material escolar, como eles se vestem... mas, em alguns casos, não todos. Olha, eu não posso julgar, mas eu acho que eles usam pra si próprios. Algum tipo de vício, coisa assim... Por isso, estou sempre alertando: Olha, crianças, este dinheiro do Bolsa Família é para vocês! Vocês têm que pedir pra mãe de vocês comprar caderno, material e roupa!

Vemos como a professora prescreve o que seria o bom uso do dinheiro, imputando à mãe a responsabilidade de investir nas crianças. Estas, em contrapartida, deveriam exigir que o gasto fosse realizado para si próprias, na medida em que o benefício é um direito seu. Esta orientação monetária se coaduna claramente com as considerações de Viviana ZELINGER (2005) sobre o dinheiro, afirmando que ele é apropriado por significados sociais, culturais e afetivos. Segundo a autora, o dinheiro representa algo além das questões monetárias; ele constrói as relações familiares, a divisão sexual do trabalho e o lugar das crianças na família. De fato, tanto que a transferência de renda aos pobres aparece como uma ferramenta de normatização sobre o gasto que deve ser dirigido politicamente e moralmente às crianças (ZELINGER, 2005).

Nesta mesma direção, Georg SIMMEL (1998) vai além da produção da classificação identitária negativa em relação aos pobres, procurando ressaltar o esquema de deveres e direitos implicados na relação entre os prestadores de serviço e os beneficiários. Se, por um lado, é dever da sociedade e do Estado combater a pobreza, por outro, é direito dos pobres receber assistência. A explicação sociológica que o autor fornece para compreender a emergência da assistência se baseia na concepção de que os pobres poderiam produzir riscos à segurança e à ordem. Assim, de acordo com essa posição, haveria um paradoxo: apesar de, moralmente, objetivar melhorar as condições de vida dos pobres, a política assistencial acaba por reproduzir o interesse de manter (e controlar) esse grupo em sua posição social e economicamente desprivilegiada.

A ideia de que a família beneficiária seria receptáculo passivo da transferência de renda ${ }^{7}$ não se apresenta aqui. Ao contrário, há (dependendo da situação) formas de negociação e de ressignificação do estatuto de beneficiário. Através das entrevistas e das conversas informais, notamos que os adolescentes tentam negociar com os pais (em maior medida, com a mãe) a possibilidade de parte de o dinheiro lhes ser concedida em forma de mesada, uma vez que há a crença coletiva de que o "Bolsa é para as crianças". Ao contrário de seus irmãos, Letícia (beneficiária, 12 anos) afirma ter vergonha de negociar com a mãe a administração do dinheiro do Programa. Foi a partir da negociação de um

${ }^{7}$ Pressuposto criticado por Serge PAUGAM (2003) e Nicolas DUVOUX (2009). 
de seus irmãos com a mãe que, hoje, os três recebem uma mesada de 10 reais; porém, este pagamento: “(...) não é todo mês não, de vez em quando. Assim, quando não tem quase nada para pagar, ela vai lá e dá, tipo, 10 reais para cada um, né? Mas quando tem conta de água e de luz mais alta, aí ela não dá".

O que mudou no ambiente familiar de Ludmila (beneficiária, 13 anos) é que, agora, ela conversa mais com a mãe, sobretudo no que tange a como gastar o dinheiro do PBF.

Eu falo pra minha mãe: Vamos dividir esse malote aí comigo? E ela diz: "Eu sempre te dou dinheiro!". A gente pede mesmo: me dá uma mesada aí! Com meus colegas eu pergunto: Sua mãe te dá dinheiro? A minha não dá não! (risos) Todo mundo lá na escola fala sobre isso. Quem não quer dinheiro? (risos).

O objetivo de se apropriar de parte do dinheiro do PBF seria para investir em sua própria vaidade. Assim, Ludmila destaca: "[...] eu ia fazer o cabelo, comprar esmalte... para ficar mais arrumada". Essa negociação entre pais e filhos, no que diz respeito à possibilidade do recebimento de uma mesada através do PBF, também é salientada por Carla: "No caso da minha família, o dinheiro do Bolsa gerou um conflito entre minha mãe e minha irmã mais nova de 16 anos que quer receber a parte dela, e minha mãe não deixa, porque ela ia botar o dinheiro fora, né?". Segundo Carla, "Minha irmã mais nova sempre diz: 'Esse dinheiro é nosso, né, mãe? R\$20,00 reais pra mim e R\$ 20,00 pro meu irmão. O que você vai fazer com o meu dinheiro?', ela fala sempre que podia comprar um DVD, um celular ou coisas do tipo".

Carla relata, ainda, que concorda com a ideia de que o benefício deve ser investido nas crianças - o que aparece nos discursos emitidos pelos professores no âmbito escolar. Ela explica que: "Eu falo para eles, quando eu pego o Bolsa... Eu falo que esse dinheiro é para vocês. Se não fosse por vocês, eu não tava recebendo". No que tange a possíveis negociações e/ou conflitos entre pais e filhos com relação ao dinheiro do PBF, Edilceia, outra beneficiária, sinaliza que:

Graças a Deus, eu nunca tive esse problema. Eu já fiquei na fila para receber, tinha uma mãe, eu não conheço, ela estava falando que ela estava na fila para receber e que o filho adolescente estava lá em baixo perto da farmácia para pegar o dinheiro. Aí ela contou que, uma vez, foi pegar o dinheiro para pagar umas contas e ele foi e empurrou ela para pegar o dinheiro. Ela quase caiu. Eu falei: Graças a Deus, eu não tenho isso.

Mesmo se a imagem tradicional da família foi construída socialmente como sagrada e imparcial em relação aos conflitos, Edilceia quebra esta imagem a partir de um exemplo ocorrido entre mãe e filho devido à inserção de um benefício no contexto familiar. Também os não beneficiários salientam a existência de tais conflitos no interior da família. Cristina (não beneficiária) comenta sobre a emergência de fofocas dentro da família, ocasionando avaliações morais sobre a forma como os beneficiários investem o dinheiro e sua legitimidade em receber o recurso. Assim, além da fofoca emergir e se reproduzir no bairro, ela também se expressa no interior da esfera familiar. Mara (não beneficiária) dá o exemplo de sua irmã que, apesar de estimulada por vizinhos a se inscrever no Bolsa Família, passou por constrangimentos morais em divulgar seu status de beneficiária dentro da sua família.

No final das contas, ela resolveu pedir, aí depois, ficou escondendo da família e, quando eles descobriram, ficou com vergonha de usar, porque todo mundo da família ficou criticando, né? Até minha mãe! A fofoca que rolava é que ela pediu por interesse, mas que não era certo. Tinha que ter deixado para outros mais pobres.

Interessante notar que, mesmo no interior destas famílias, há uma cobrança para que seus membros não se candidatem ao Bolsa Família, o que faria com que escapassem 
do enquadramento externo de beneficiários (e toda decorrência que deriva daí). Talvez esta resistência familiar se deva à vontade de proteger seus membros de possíveis situações de humilhação e à percepção de justiça que deveria dirigir o recurso a outros que necessitam mais.

A introdução do PBF (que pretende "quebrar com o ciclo intergeracional da pobreza" e estabelecer condicionalidades relacionadas ao bem-estar dos filhos) tem produzido questionamentos por parte dos adolescentes sobre a administração materna do recurso. Abre-se, portanto, um processo constante de negociações e tensões sobre o destino da renda transferida, o que tende a causar um impacto sobre a legitimidade de quem seria o indivíduo mais qualificado na família para gerir o recurso assistencial. Esta negociação do poder parental (ou melhor, maternal) não acontece quando se trata de crianças; nestes casos, a não partilha do gasto se justifica pela ideia de que eles são "seres em desenvolvimento", ainda incapazes de discernir sobre o 'bom' uso do dinheiro. Entre os adolescentes, no entanto, o poder de negociação é maior, mesmo se é ainda a mãe que faz a distribuição do recurso (via 'mesada').

\section{Fronteiras interfamiliares}

Inicialmente, vemos uma oposição simbólica entre 'beneficiária feliz' (que conseguiu receber o Bolsa Família) e 'candidata invejosa' (que tentou ou tem vontade de tentar e não obteve sucesso). Estas avaliações se respaldam em percepções de ressentimento e ciúme.

Simone (beneficiária) acredita que os vizinhos que não recebem o Bolsa Família "[...] têm olho grande. Eu não sei o que eles pensam, mas que têm olho grande ah... isso têm! Tem muita gente que queria estar recebendo, mas fica com vergonha". Elisabeth (beneficiária) abandonou o Pró-Jovem Urbano ${ }^{8}$ porque não podia comparecer, por problemas de saúde. Mesmo com o atestado médico em mãos, "cortaram meu Bolsa Família". Além disto, afirma ter presenciado um conflito, quando fazia o Pró-Jovem, entre mães que tentaram e não conseguiram e mães que tentaram e conseguiram: "A gente que conseguiu fica feliz, né? Elas que não conseguiram ficam com inveja, fica querendo 'futucar' nossa vida".

Mesmo Cacilda (Agente de Saúde) nota certa 'inveja' (e ressentimento) por parte dos 'pobres não beneficiários' (que não obtiveram sucesso na demanda) com relação aos bolsistas do PBF. Este sentimento às vezes culmina em denúncias e fofocas contra os beneficiários. De acordo com Cacilda, as denúncias em Nova Cidade são feitas

[...] pelos próprios vizinhos... Mas não se pode fazer denúncia por inveja porque a pessoa acha que ganha menos que outra ou por preconceito. As coisas têm que ser claras. Mas como te falei antes, a maior parte das denúncias são os próprios vizinhos que fazem um do outro, porque, assim, quando um compra alguma coisa e o outro acha que não tinha o direito de ter, de comprar. Ou então, é de alguém que tenta e não consegue, aí arruma um jeito de falar mal do que ganha. Então pensa que ele não precisa do benefício.

Por fim, podemos notar que a maioria dessas denúncias aponta para a geração de um conflito (ora através do ciúme, ora através do ressentimento) entre pessoas que solicitaram o benefício, mas não conseguiram, e pessoas que obtiveram sucesso em sua demanda.

\footnotetext{
${ }^{8}$ O Pró-Jovem Urbano pretende promover a inclusão social dos jovens de 18 a 29 anos que não concluíram o Ensino Fundamental. O objetivo é reinserir estes jovens na escola e no mundo do trabalho, de modo a propiciarIhes oportunidades de emprego e de exercício efetivo da cidadania. O Programa possui duração de 18 meses oferecendo formação no Ensino Fundamental, em cursos de capacitação profissional e em aulas de informática, tendo como auxílio uma bolsa de R\$ 100,00 por mês. À época, foram consultados dois sites a respeito: www.mds.gov.br e http://www.projovem.gov.br/site/interna.php? $p=$ material\&tipo=Conteudos\&cod=22.
} 
Mais surpreendente ainda é que, mesmo entre os beneficiários, vemos emergir um conflito em torno da legitimidade do valor do benefício, quando questionamentos são feitos acerca de por que uns recebem um valor pequeno e outros recebem um valor mais alto.

\section{Algumas considerações}

Vimos como, de modo não intencional, o Programa Bolsa Família conduz a consequências sociais distintivas entre 'pobres': beneficiários e não beneficiários de tal programa. Apesar de haver uma forte tendência na arena pública em definir os 'pobres' pela sua condição econômica, eles próprios utilizam outros critérios (tipicamente morais) de auto e alter classificação da pobreza. Usam, especificamente, padrões de julgamento a partir de suas posições frente ao Programa, produzindo distinções simbólicas em torno de critérios como: 'necessidade', 'merecimento', 'sofrimento', 'honra' e 'padrões comportamentais generificados'.

Sob a égide de correlações estatísticas que mapeiam a vulnerabilidade social, o Estado tem utilizado seu poder de nomeação para distinguir grupos 'pobres' de 'não pobres', julgando a necessidade de cuidados e múltiplos controles. O critério econômico opera como um elemento legítimo que definirá 'merecedores' e 'não merecedores' de um benefício assistencial. Todavia, este critério "objetivo" - incorporado como regra no Programa Bolsa Família - é constantemente ressignificado, havendo uma margem de interpretação das normas estatais pelos operadores locais da política. As políticas de transferência de renda, em particular o Programa Bolsa Família, estabelecem múltiplos controles sobre a população beneficiária que serão (re)negociados no contexto interacional.

Ao contrário da clara incorporação (e, portanto, da naturalização) das regras da política, os agentes institucionais aderem a valores morais específicos do 'bom pobre' e do 'merecedor'. Nesse sentido, não parece haver uma correspondência coerente entre a classificação do Estado e a incorporação automática dos indivíduos aos seus princípios gerais; ao contrário, valores morais complexos regem as relações sociais locais.

Verificamos que a própria comunidade constrói hierarquias (principalmente através das categorias de 'sofrimento' e de 'necessidade'), distinguindo grupos moralmente: 'trabalhadores' e 'vagabundos'; 'bons' e 'maus pobres' e 'merecedores' e 'aproveitadores'. Assim, o julgamento dos beneficiários para legitimar (ou não) uma família como 'merecedora' do benefício baseia-se em diversas variáveis, tais como: 1) idade - as mães novas possuem menor legitimidade que as outras, tendo em vista que poderiam ser mão de obra ativa no mercado de trabalho; 2) tipo de família - principalmente em relação ao número de crianças no lar (quanto maior o número, maior deveria ser o apoio do Estado); 3) bens materiais - se possuem muitos bens, significa que a família não se configura como 'pobre' e, portanto, não merece o auxílio e 4) condições de trabalho - se possuem emprego formal, têm menor legitimidade para o recebimento do benefício.

Há também outro tipo de julgamento de valor em relação ao uso do dinheiro do BF. Assim, as mulheres titulares legais que investem em si próprias são julgadas como 'não merecedoras do benefício', pois estariam rompendo, por um lado, com a lógica tradicional da maternidade e, por outro, estariam sendo 'egoístas' com um recurso que deveria segundo as orientações do Programa e as moralidades locais - ser investido na família. Já aquelas que investem na família, sobretudo nas crianças, são valorizadas e legitimadas pelo grupo de beneficiárias.

A partir dos dados empíricos, observamos que a relação dos beneficiários com seus vizinhos (e com os atores institucionais) funda-se em uma matriz moral, relacionada à emergência de fronteiras simbólicas pautadas nas noções de reputação, status, mérito, 
performance afetiva e padrões de conduta. Por fim, verificamos que as avaliações sobre a 'beneficiária legítima' - feitas pelos não beneficiários e também pelos atores institucionais - têm como registro principal a lógica do gênero, respaldada no julgamento de 'boa' e 'má mãe'.

\section{Referências}

ANDERSON, Elijah. Code of the Street: Decency, Violence, and the Moral Life of the Inner City. New York: W. W. Norton, 1999.

BRÍGIDO, Carolina. "Presidente de Pastoral da CNBB diz que a Bolsa Família é 'assistencialista' e 'vicia'”. Globo.com, Brasília, 17/1 1/2006. Disponível em: http://oglobo.globo.com/pais/ mat/2006/1 1/17/286708508.asp. Acesso em: 10/10/2011.

CASTRO, Jorge Abrahão de; MODESTO, Lúcia (Orgs.). Bolsa Família 2003-2010: avanços e desafios. Brasília: IPEA, 2010. 1v.

DUVOUX, Nicolas. L' autonomie des assistés. Sociologie des politiques d' insertion. Paris: PUF, 2009.

FINE, Ben et al. Development policy in the twenty-first century: beyond the post-Washington Consensus. Londres: Routledge, 2001.

FONSECA, Marília. "O Banco Mundial como referência para justiça social no terceiro mundo: evidências do caso brasileiro". Revista da Faculdade de Educação, São Paulo, v. 24, n. 1, p. 37-69, 1998.

FOUCAULT, Michel. Vigiar e Punir: nascimento da prisão. 37.ed. Petrópolis: Vozes, 2009.

GOFFMAN, Erving. Manicômios, prisões e conventos. São Paulo: Perspectiva, 1987.

JENSON, Jane. "Lost of translation: the social investment perspective and gender equality". Social Politics: international Studies in Gender, State and Society, 2009, v. 16, n. 4, p. 446483.

LIMA, Antônia Jesuíta de. As multifaces da pobreza. Formas de vida e representações simbólicas dos pobres urbanos. Teresina: Halley, 2003.

OLK, Thomas. "Children in the 'Social Investment State'”. In: WELLCHI NETWORK CONFERENCE 2, Centre for Globalisation and Governance, University of Hamburg, 2006.

ORLOFF, Ann Shola. "Farewell to Maternalism? State Policies and Mothers' Employment". Institute for Policy Research, Evanston, Northwestern University, 2005. (Working Paper Series)

PAUGAM, Serge. Desqualificação social: ensaio sobre a nova pobreza. São Paulo: Cortez, 2003.

PIRES, Flávia; REGO, Walquiria (Orgs.). "Dossiê 10 anos do Programa Bolsa Família". Revista de Ciências Sociais, Política e Trabalho, n. 38, 2013.

REGO, Walquiria G. Domingues Leão; PINZANI, Alessandro. Vozes do Bolsa Família: autonomia, dinheiro e cidadania. São Paulo: EDUnesp, 2013.

SCHILD, Verónica. "Empowering 'consumer-citizens' or governing poor female subjects? The institutionalization of 'self-development' in the Chilean social policy field". Journal of Consumer Culture, n. 7, p. 179-203, 2007.

SIMMEL, Georg. Les pauvres. Paris: PUF, 1998.

SORJ, Bila \& GOMES, Carla. "O gênero da 'Nova Cidadania': O Programa Mulheres da Paz". Revista Sociologia \& Antropologia, v. 1, n. 2, p. 147-164, 2011.

STROBEL, Pierre. Penser les politiques sociales. Contre les inégalités: le principe de solidarité. La tour d'Aigues: Éditions de l' Aube, 2008.

ZELINGER, Viviana. La signification sociale de l' argent. Paris: Seuil, 2005. 


\section{The 'Feminine' as Gender of Development}

Abstract: This article aims to analyze, from a gendered perspective, in which ways the construction of moral and symbolic boundaries resulting from the implementation of a program to reduce poverty, the Bolsa Familia, are developed in a non-premeditated manner. We seek to clarify the nature of these boundaries and the negotiations of their content. In order to better understand the complexity of the status formation process of the beneficiaries (mothers), we have been present through different places through which the beneficiaries move. By means of interviews conducted in a periphery of Rio de Janeiro we can affirm that the relations between the beneficiaries and the nonbeneficiaries are based on a moral matrix which encompasses tensions in the evaluation of gender ('good' and 'bad mother'), which also reproduces a hierarchy of 'good' and 'bad' poor.

Keywords: Gender; Symbolic Boundaries; Bolsa Família Program

[Recebido em 02/06/2015, reapresentado em 22/08/2016 e aprovado em 02/03/2017]

Mani Tebet Azevedo de Marins (manitebetufrijgmail.com) é Professora Adjunta de Sociologia da UFRRJ e Professora da Pós-Graduação em Políticas Públicas em Direitos Humanos da UFRJ. Doutora em Sociologia pelo Programa de Pós-Graduação em Sociologia e Antropologia (PPGSA) da UFRJ. Suas pesquisas se concentram em quatro grandes temas: políticas públicas, educação, gênero e relações raciais. A autora possui artigos publicados no Scielo. Sua publicação mais recente encontra-se na Revista Sociologia e Antropologia (PPGSA-UFRJ), v. 04, outubro 2014, sob título "Os repertórios morais e estratégias individuais de beneficiários do Bolsa Família".

\section{Errata}

Nas páginas 1 e 14, onde se lia:

Marins Tebet Azevedo

Leia-se:

Mani Tebet Azevedo de Marins

Revista Estudos Feministas, Florianópolis, 26(1): errata, janeiro-abril/2018

14 Revista Estudos Feministas, Florianópolis, 26(1): e39010 